\title{
Field survey of air conditioner temperature settings in a hot, dry climate (Oman)
}

\section{$\operatorname{AUTHOR(S):~}$}

Majid, Noor Hanita Abdul; Takagi, Nozomi; Hokoi, Shuichi; Ekasiwi, Sri Nastiti N.; Uno, Tomoko

\section{CITATION:}

Majid, Noor Hanita Abdul ... [et al]. Field survey of air conditioner temperature settings in a hot, dry climate (Oman). HVAC\&R Research 2014, 20(7): 751-759

\section{ISSUE DATE:}

2014-10-06

URL:

http://hdl.handle.net/2433/200279

\section{RIGHT:}

This is an Accepted Manuscript of an article published by Taylor \& Francis in 'HVAC\&R Research' on 06 Oct 2014, available online: $h$ ttp://www.tandfonline.com/10.1080/10789669.2014.953845; The full-text file will be made open to the public on 06 Oct 2015 in accordance with publisher's 'Terms and Conditions for Self-Archiving'.; This is not the published version. Please cite only the published version.; この論文は出版社版でありません。引用の際には出版社版 をご確認ご利用ください。 


\title{
Field Survey of Air Conditioner Temperature Settings in a Hot, Dry Climate (Oman)
}

\author{
Noor Hanita Abdul Majid, PhD Nozomi Takagi, Shuichi Hokoi, PhD \\ Sri Nastiti N. Ekasiwi, PhD \\ Member ASHRAE \\ Tomoko Uno, PhD
}

\begin{abstract}
In conventional air conditioning design, the comfortable range of temperatures is 25 to $27^{\circ} \mathrm{C}$, with relative bumidity levels of 40 to $60 \%$; these numbers vary only slightly based on a person's race and country. Several studies in tropical climates show that the observed thermal comfort requirement often does not agree with those obtained based on experiments mainly using North American subjects. However, there is no consistent rationale that explains why the comfort requirements are different in a bot climate, suggesting more surveys on thermal comfort may be needed in the tropics.

In Asia, there has recently been a rapid and widespread diffusion of air conditioners. Therefore, we conducted a survey to clarify what temperature and humidity level people in Asian countries prefer in order to feel comfortable. Following that research, this article presents the results of a questionnaire survey on the use of air conditioners in houses in hot, dry climates.

Nizwa and Rustak, Oman, which are characterized by the hot, arid climate of the Arabian Peninsula, were chosen as survey areas. The questionnaire survey was distributed to students of Nizwa University. Questions were asked about the duration of air conditioner use and the preferred air conditioner temperature setting. In order to determine how respondents felt about their indoor environment, we also asked about the thermal sensations that were experienced while using the air conditioner. In both cities, the mean operating time of the air conditioner was very long. The respondents reported selecting a low temperature setting while sleeping despite the fact that many of them reported that they were cold while sleeping. Ninety percent of respondents reported a cold, cool, or neutral thermal sensation while using the air conditioner, without feeling discomfort.
\end{abstract}

\section{INTRODUCTION}

In conventional air conditioning design, the comfortable range of temperatures is 25 to $27^{\circ} \mathrm{C}$, with relative humidity (RH) levels of 40 to $60 \%$ (ASHRAE 2005); these numbers vary only slightly based on a person's race and country (Fanger 1970). However, the authors have frequently experienced conference halls and hotels in Indonesia and Singapore that are maintained at very low temperatures, which seems inconsistent with these research results. Fanger has proposed a predicted mean vote (PMV), based on the comfort equation and predicted percentage of dissatisfaction (PPD) on which the international thermal comfort standard ISO7730 is based. Although the comfort equation is based on experiments using North American subjects, the application of the equation to other groups has been discussed. Several studies on thermal comfort in tropical climates have been conducted (Busch 1992; Nicol 1973, 2004; Sharma et al. 1986), and these studies

N. Hanita A.M. is an associate professor, International Islamic University, Kuala Lumpur, Malaysia. N. Takagi is an engineer, Obayashi Corporation, Tokyo, Japan. S. Hokoi is a professor, Kyoto University, Kyoto, Japan. S. Nastiti N.E. is an associate professor, Institute Technology SEPULUH NOPEMBER, Surabaya, Indonesia. T. Uno is a lecturer, Mukogawa Women's University, Nishinomiya, Japan. 
show that the observed thermal comfort requirement in hot climates is not in firm agreement with that dictated by the thermal comfort equation. However, there is no reasonable and consistent rationale that explains why the comfort equation does not adequately describe comfortable conditions in a hot climate. On the other hand, de Dear et al. (1991) conducted an experiment in Singapore in which climate chamber subjects adjusted the temperature according to their wishes. At the observed preferred temperature, the mean thermal sensation was significantly lower than neutral, which indicates that subjects prefer cool conditions. International thermal comfort standards define the neutral temperature obtained from physical measurement and the American Society of Heating, Refrigerating, and Air-Conditioning Engineers (ASHRAE) thermal sensation scale as a measure of comfort. However, as these field studies show, more surveys on thermal comfort may be needed in different climatic regions such as the tropics.

In Asia, which is generally a hot and humid climate region, people are somewhat used to controlling their indoor thermal environment by using external air flow (Kubota et al. 2006), and most researchers have focused on the cooling effect of natural ventilation. However, there has recently been a rapid and widespread diffusion of air conditioners (Ministry of Internal Affairs and Communications. 2002). Thus, people seem to prefer a cool indoor environment (Uno et al. 2003). Therefore, we conducted a survey to clarify what temperature and humidity level people in these regions prefer in order to feel comfortable, using a questionnaire survey and measurements of indoor thermal environments (Nastiti et al. 2013). Following that research, this paper presents the results of a questionnaire survey on the use of air conditioners in houses in hot, dry climates. The objective of the survey was to clarify what temperature and humidity levels people in hot, dry regions prefer in order to feel comfortable, with a special focus on their sleeping environment.

\section{OUTLINE OF SURVEY}

\subsection{Studied area}

Two cities in Oman, Nizwa $\left(\mathrm{N} 23^{\circ} \mathrm{E} 57^{\circ}\right)$ and Rustak $\left(\mathrm{N} 22^{\circ} \mathrm{E} 57^{\circ}\right)$, which are characterized by a hot and arid climate, were chosen as the survey areas. The annual variations in air temperature, and relative humidity in the two cities are shown in Figures 1 and 2, along with those of Tokyo (Data from World Organization 2002). From April to October, the monthly mean air temperatures are over $30^{\circ} \mathrm{C}$, and the daily highest temperature reaches $40^{\circ} \mathrm{C}$ in July. The daily amount of solar radiation ranges from 14 to $22 \mathrm{MJ} / \mathrm{m} 2 /$ day (Figure 3). Conversely, the daily lowest temperature in January is nearly $10^{\circ} \mathrm{C}$. There is a small amount of precipitation throughout the year, from 0.5 to $19 \mathrm{~mm} / \mathrm{month}$ (Figure 4).

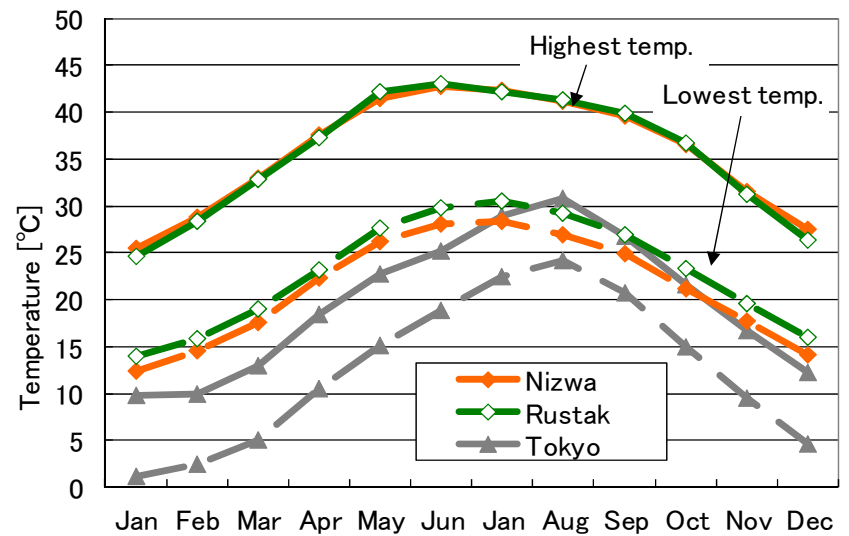

Figure 1. Outdoor temperature of Nizwa and Rustak.

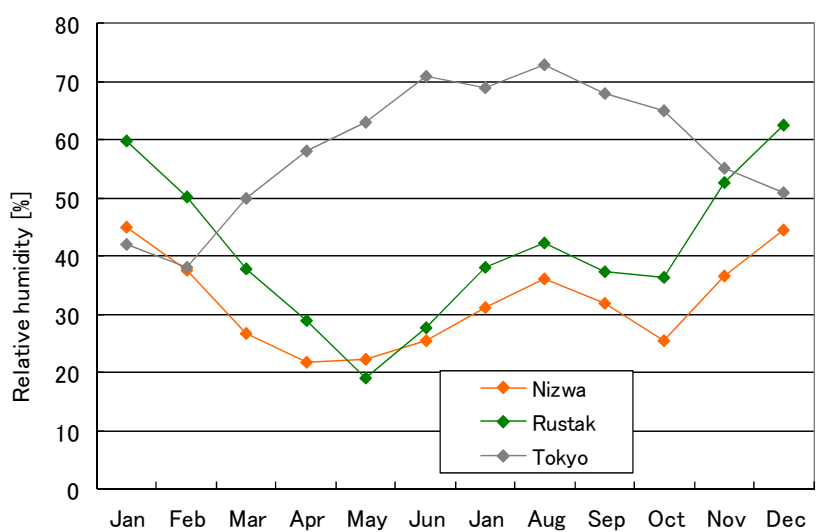

Figure 2. Relative humidity of Nizwa and Rustak. 


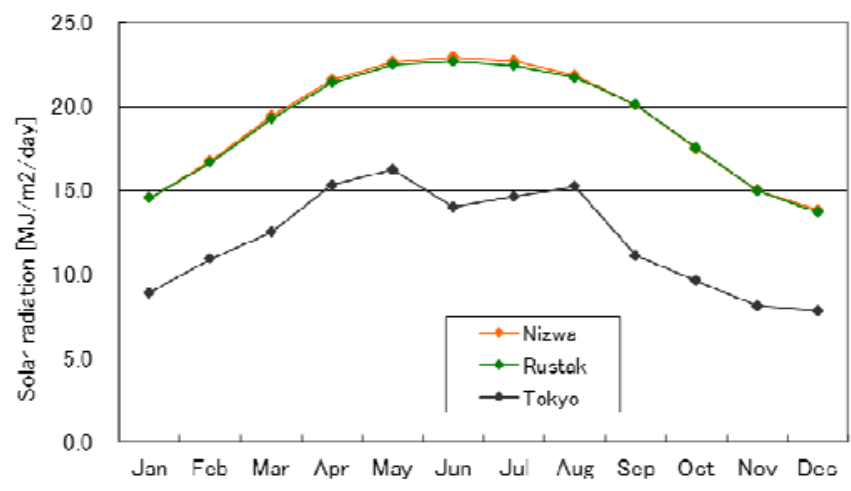

Figure 3. Solar radiation of Nizwa and Rustak. Rustak.

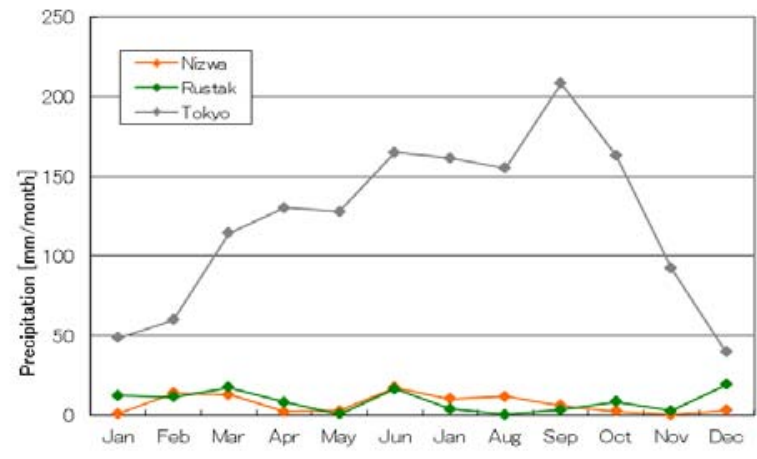

Figure 4. Monthly precipitation of Nizwa and

\subsection{Respondents and period of survey}

Residential buildings were chosen for the survey instead of non-residential buildings because the occupants have a greater chance of being able to choose their preferred temperature setting for the air conditioner. Conference halls and hotel lobbies are designed for public use, so some of the occupants may have to endure conditions that are set to accommodate the comfort level of the average person. Therefore, in order to achieve the authors' objectives, measurements in residential buildings and responses from their residents were used in this research.

The questionnaire survey was given to 87 students in the Architectural Department of Nizwa University. The survey was carried out three times: in the first quarter of 2010, in June 2011, and in October 2011. Table 1 shows the time of the survey, number of respondents, and questionnaire items. These surveys were handed out during class, and the students were directed to fill them out at home in both cities. They were then collected in a later class.

Table 1. Questionnaire for Residents

\begin{tabular}{|c|c|c|c|}
\hline No. of Survey & Survey Period & Number of Reports & Questionnaire Items \\
\hline First time & Jan. Mar., 2010 & 22 (Nizwa) & DAbout your home \\
\hline Second time & June 2011 & $\begin{array}{l}12 \text { (Nizwa), } \\
14 \text { (Rustak) }\end{array}$ & $\begin{array}{l}\text { Your family, Type of house, Number of stories, } \\
\text { Structure of house, Electric appliances, Plan of } \\
\text { house, Users of the bedroom, Opening and } \\
\text { closing of windows, Electricity charge, Clothing } \\
\text { during sleep, Annual income }\end{array}$ \\
\hline Third time & October 2011 & 39 (Rustak) & $\begin{array}{l}\text { Use of air-conditioners (AC) } \\
\text { Manufacturer and price, Usage time of AC, Set } \\
\text { point temperature of AC, Health, Necessity of } \\
\text { AC, Electricity use, Economic effects of using } \\
\text { AC, Countermeasures when cold in the } \\
\text { bedroom, thermal environment in the bedroom } \\
\text { during normal use of an AC (set-point } \\
\text { temperature, thermal sensation, comfort } \\
\text { sensation, more favorable environment) }\end{array}$ \\
\hline
\end{tabular}

\subsection{Questionnaire items}

In order to comprehensively understand the circumstances surrounding the use of air conditioning in these cities, the questionnaire items included not only the use of an air conditioner but also information about living conditions. For 
example, the questions regarding living conditions asked about the number of family members, house layout, house construction, surrounding environment, income, and electrical appliances owned by the household. Questions concerning the use of air conditioners asked about the duration of air conditioner use and the air conditioner temperature setting. The first questionnaire results revealed that most respondents used an air conditioner for a long time while sleeping. Therefore, to determine how the respondents felt about their indoor thermal environment while using an air conditioner, the authors also asked about the thermal sensations that they experienced while using the air conditioner, the clothing worn while sleeping, and any health problems reported while using the air conditioner. Further details are given in the appendix.

\section{RESULTS OF SURVEY}

\subsection{Results of living conditions}

a) Family members. The average household size was 6.7 persons among the Nizwa respondents and 7.2 persons among the Rustak respondents. More than $90 \%$ of people live in a detached house called a "villa" or apartment house.

b) Monthly household income and electricity charges. Figure 5 shows the monthly household incomes of the respondents' families. Among the respondents in both cities, about $50 \%$ of families had a monthly income of less than 10,000 OMR (25,000 USD, $1 \mathrm{USD}=0.385 \mathrm{OMR})$, whereas 10 to $20 \%$ of families had incomes of 40,000 OMR or more.

Figure 6 shows the monthly electricity charges for the respondents. In both cities, more than $70 \%$ of families had monthly electricity charges of less than 100 OMR. The mean monthly electricity charge is 70 OMR in Nizwa and 68 OMR in Rustak. In Oman, the subsidiary for energy use is paid by the government, and the electricity charge for kWh is about $0.011 \mathrm{OMR} / \mathrm{kWh}$ for the use of up $3,000 \mathrm{kWh}$. Therefore, the net consumption of electricity is significant, although the electricity charges are not particularly high.

c) Number of air conditioners. The air conditioners owned per family was 5.9 in Nizwa, 6.9 in Rustak, and 2.5 in Japan. Figure 7 shows the room where the air conditioner was installed. In particular, the installation rate in bedrooms is very high in both cities in Oman, almost $100 \%$, which means great value is placed on the thermal environment during sleep. In the living room, the guest room, and the kitchen, the installation rates are higher than $60 \%$. From these high installation rates, it is clear that having air conditioning has become a priority for many citizens.

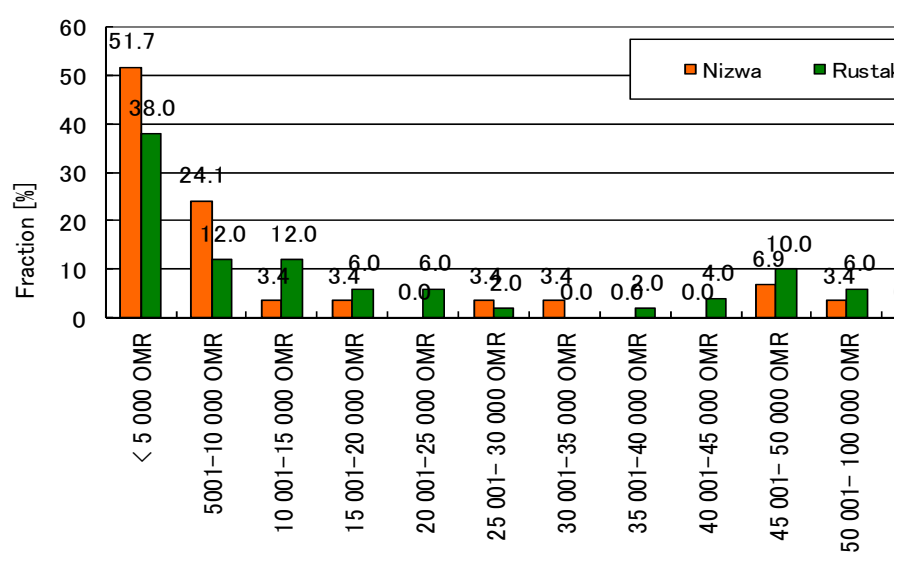

Figure 5. Monthly household income.

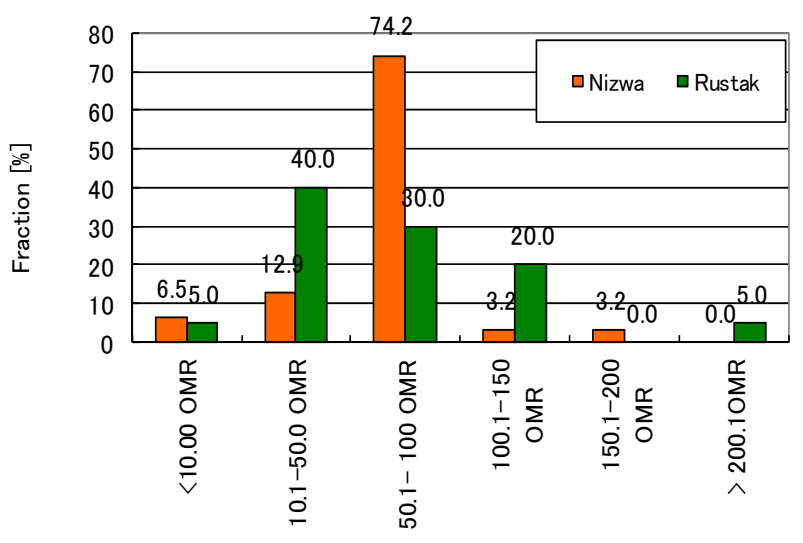

Figure 6. Monthly electricity charges. 


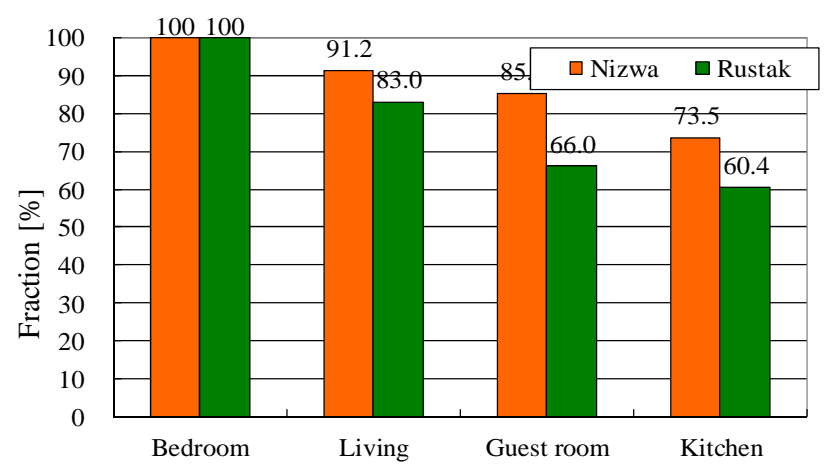

Figure 7. Room where air conditioner was installed.

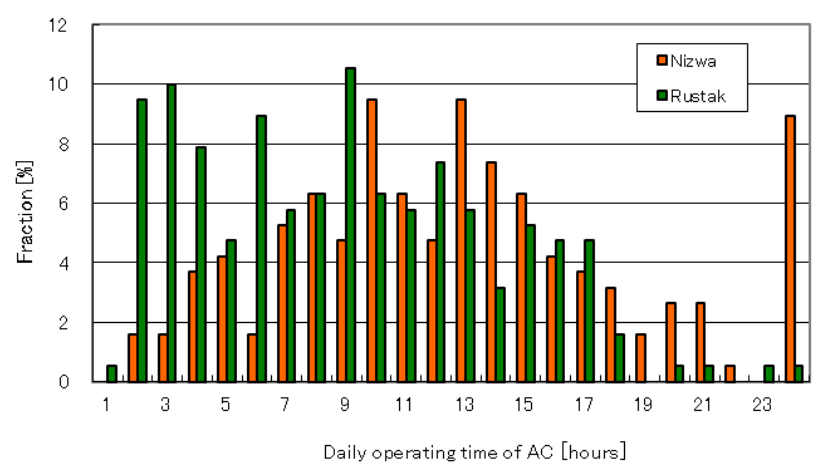

Figure 8. Daily operating time of air conditioner (hours)

The following items were answered by each user with an air conditioner in their bedroom (107 respondents in total in Nizwa and 195 in Rustak).

d) Operating time of air conditioners. Figure 8 shows the daily operating times of air conditioners. The longest period of use was 24 hours in both cities ( $9 \%$ in Nizwa); the average use was 12.8 hours in Nizwa and 9.1 hours in Rustak.

e) Temperature settings of air conditioners. Figure 9 shows the temperature settings of the respondents' air conditioners. There are two peaks, one centered at around $18^{\circ} \mathrm{C}$ and the other centered at $25^{\circ} \mathrm{C}$ in Nizwa, while more than half the people in Rustak set it lower than $20^{\circ} \mathrm{C}$. The average temperature settings were $21.6^{\circ} \mathrm{C}$ in Nizwa and $19.7^{\circ} \mathrm{C}$ in Rustak. These values are rather low for environmental temperature settings for sleeping.

f) Thermal sensations while sleeping. Figure 10 shows the thermal sensations the respondents reported while sleeping. Surveys on thermal sensations usually use votes based on the ASHRAE seven-point scale. However, in this survey, the respondents were asked to rate the thermal sensation based on a five-point scale ranging from cold (1) to hot (5), with neutral (3) in the middle for ease of response.

While sleeping, $68 \%$ of respondents in Nizwa and 65\% in Rustak reported thermal sensations of 1 or 2 (2=cool); votes of 1, 2, and 3 accounted for $88 \%$ and $95 \%$ of the total votes in Nizwa and Rustak, respectively. The most common level of sensation among the Nizwa respondents was $2(37 \%)$, whereas it was 1 (41\%) for the Rustak respondents, and more people chose 1 than 3 (neutral). The averages were 1.5 in Nizwa and 2.1 in Rustak. The air conditioners were set to temperatures that created cold or cool thermal sensations.

g) Comfort sensations. The percentage of respondents who reported a "very comfortable" comfort sensation was the highest in both cities, $46 \%$ in Nizwa and 51\% in Rustak (Fig. 11).

h) Favorable environment. Figure 12 shows the favorable environments. In Nizwa, the respondents reported "as it is" (70\%), "cooler" (18\%), then "warmer" (12\%), respectively. In Rustak, "cooler" and "as it is" had almost the same number of respondents. Favoring a "warmer" environment had the lowest percentage of respondents $(\sim 10 \%)$ in both cities.

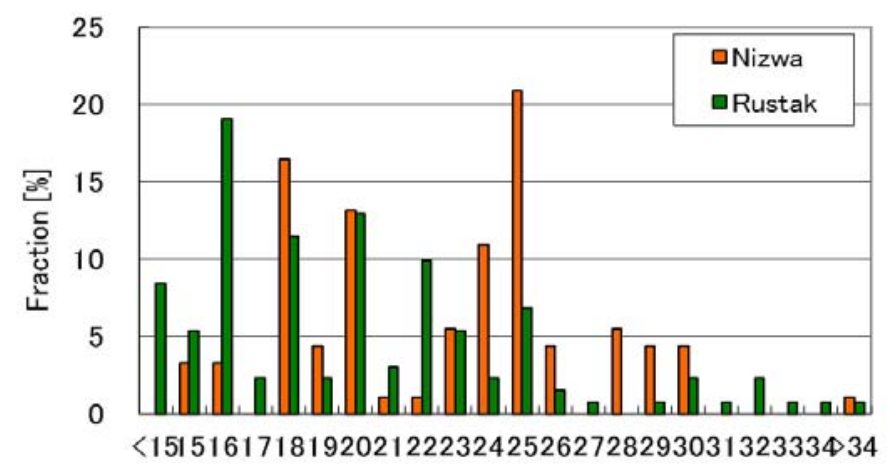

Figure 9. Set-point temperature of air conditioner.

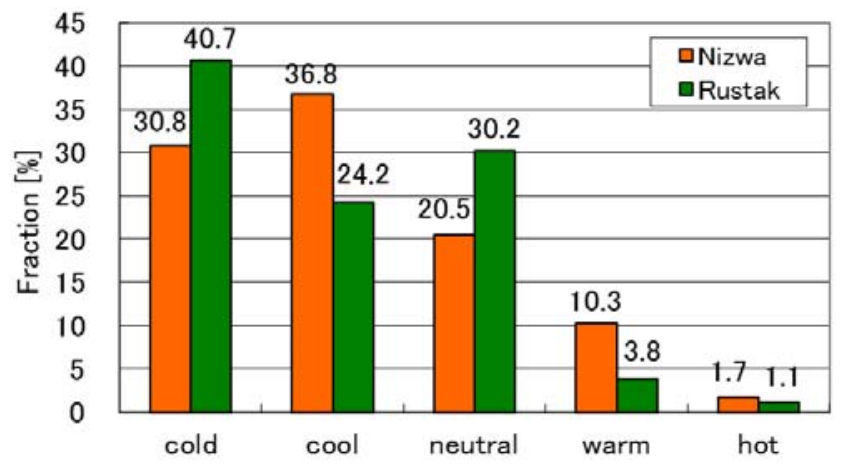

Figure 10. Thermal sensation during sleep. 


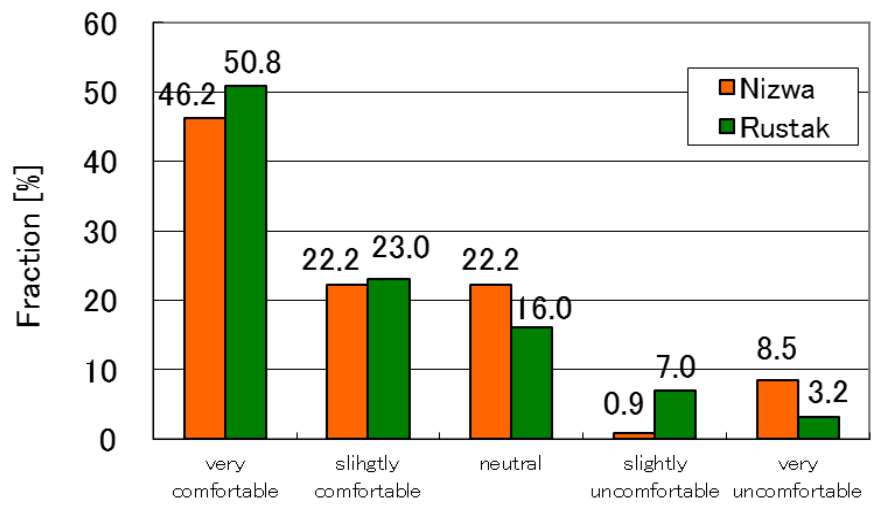

Figure 11. Comfort sensation.

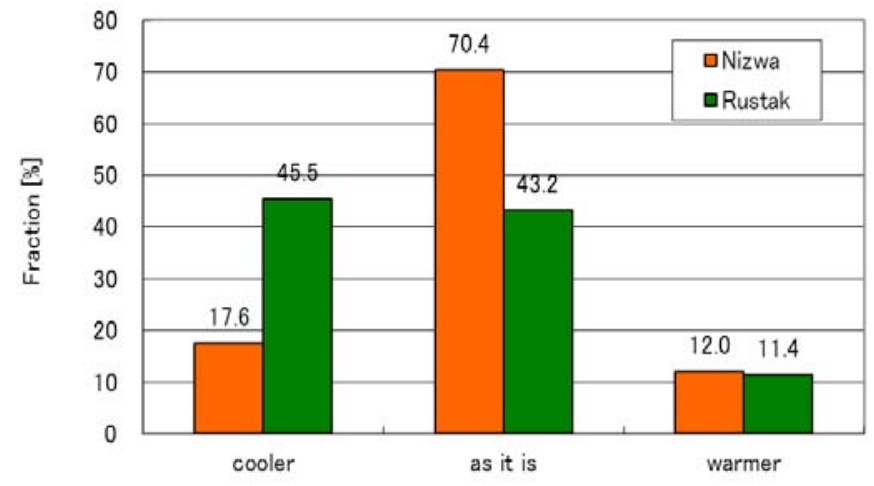

Figure 12. Favorable environment.

i) Health problems. Although the majority of respondents in both cities reported having no health problems, about half $(43.8 \%)$ of the respondents in Nizwa and 38.5\% of respondents in Rustak complained of some health problems while staying in an air-conditioned room (Figure 13). It seems clear that these health problems were partly related to using air conditioners set at low temperatures.

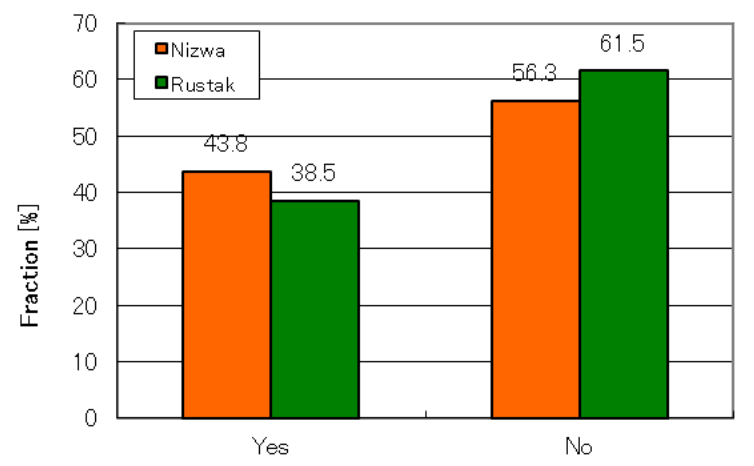

Figure 13. Percentage of health problems reported by survey participants.

\subsection{Thermal and comfort sensations}

Figure 14 shows the breakdown of comfort sensations within each thermal sensation. The numbers shown indicate the number of respondents who reported a specific sensation. In both cities, the number of residents who reported having a "cold" or "cool" thermal sensation and a "very comfortable" or "comfortable" comfort sensation was quite high. The percentage was 55\% for Nizwa respondents and 53\% for Rustak respondents.

Thus, most respondents did not consider being cool or cold as negative. On the other hand, fewer people reported having a "neutral" thermal sensation and being very comfortable or comfortable than reported having a cold or cool thermal sensation and being very comfortable or comfortable. Thus, the respondents tended to feel more comfortable in cold or cool environments than in neutral environments.

Figure 15 shows the breakdown of favorable environments for each thermal sensation. Many respondents desired a cooler environment regardless of the thermal sensation they experienced, particularly in Rustak. Interestingly, among people who reported being cold or cool, $25 \%$ of respondents in Nizwa and about $50 \%$ of respondents in Rustak wanted a "cooler" environment, which was much higher than the number of respondents who wanted a "warmer" environment. It is clear that people who reported both a cold thermal sensation and a desire for a cooler environment do not regard the sensation of being cold as uncomfortable. 


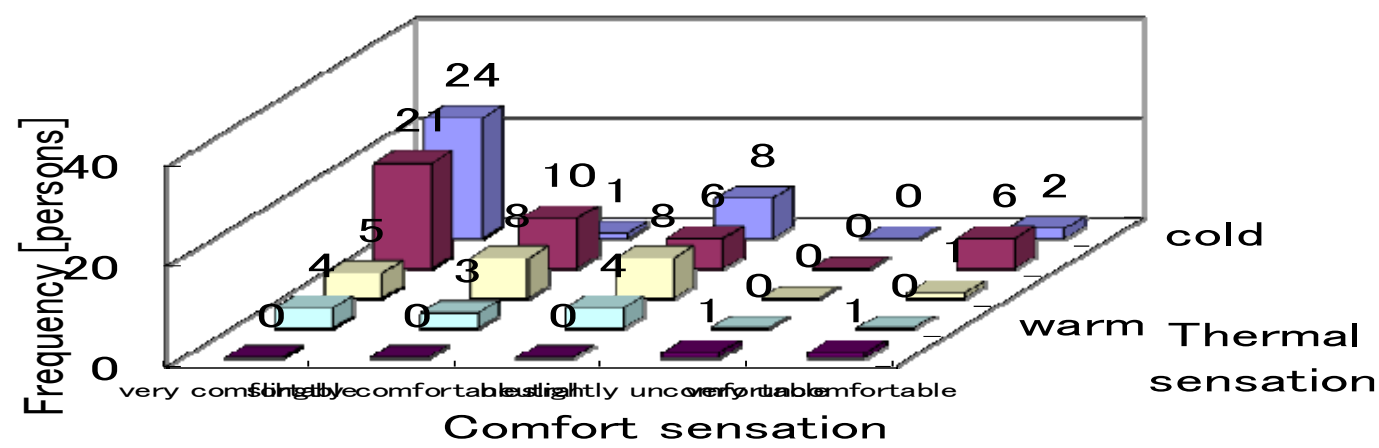

A) Nizwa

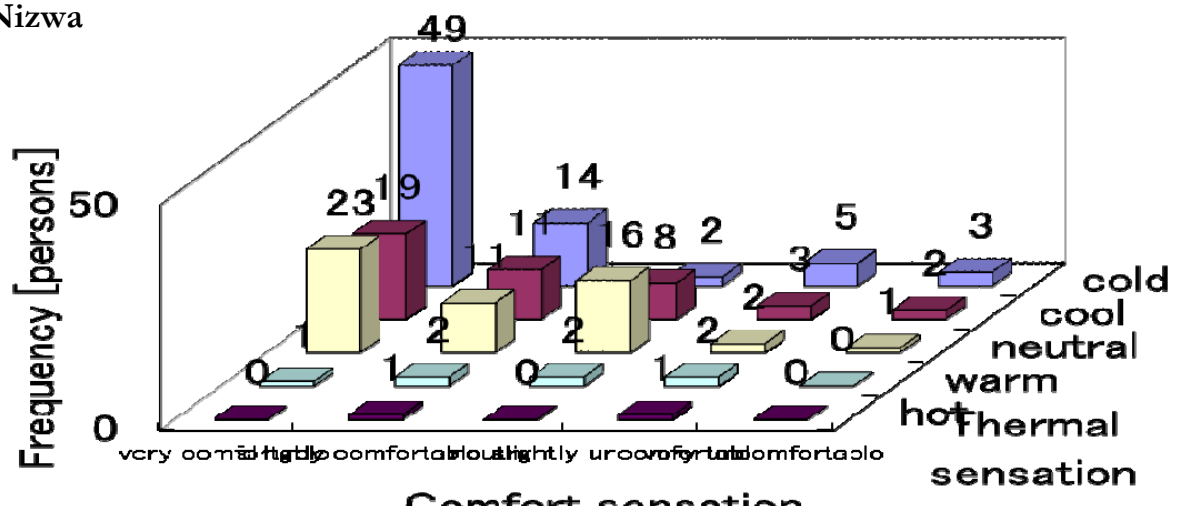

B) Rustak

Comfort sensation

Figure 14. Breakdown of sensation of comfort in each thermal sensation

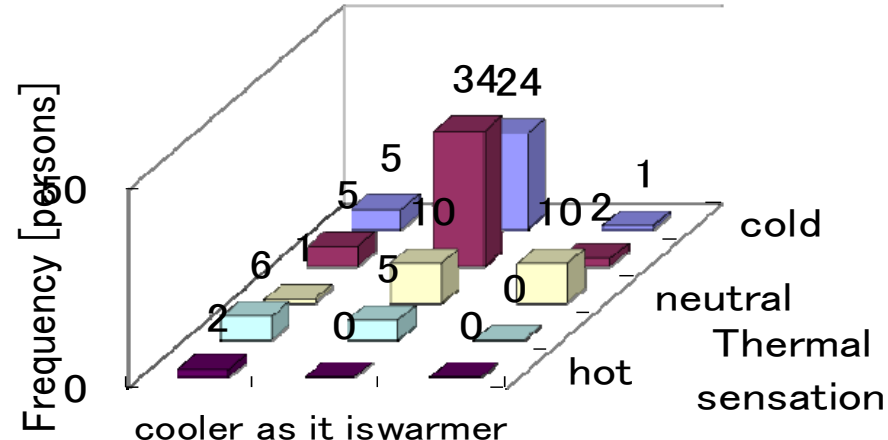

favorable environment

A) Nizwa

B) Rustak

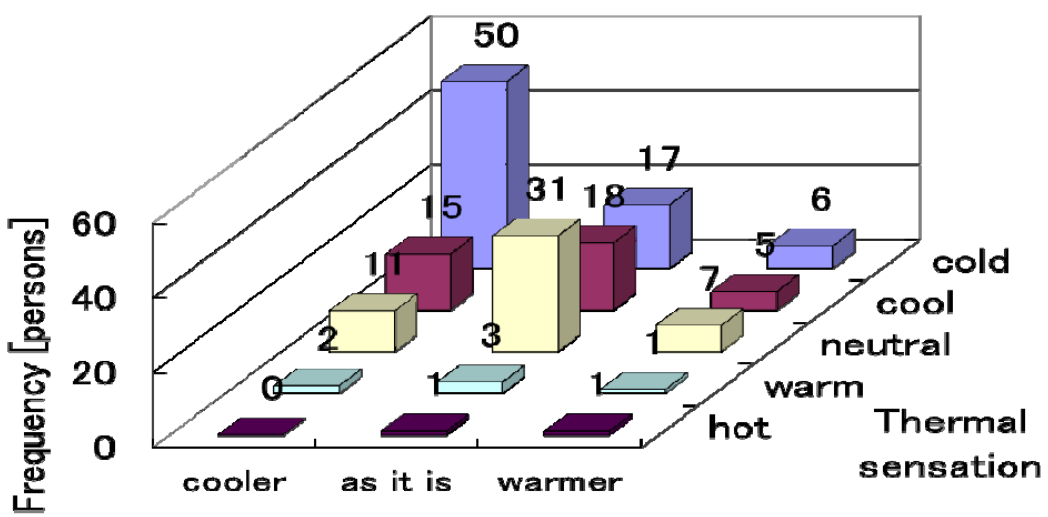

Favorable environment

Figure 15. Breakdown of favorable environment in each thermal sensation 


\section{MEASUREMENT OF INDOOR THERMAL ENVIRONMENT}

\subsection{Outline of measurement}

In order to understand the relationship between the indoor thermal environment and thermal sensations, we measured the indoor air temperature and RH levels. In this section, a part of the measured results is shown that was obtained in four residential buildings in Nizwa for November 20 to 22, 2011. The temperature and humidity were measured in the living- and bedrooms of each house using handy-type hygro-thermometers.

\subsection{Measured results}

a) Residence $\mathbf{A}$ (Figure 16): In the bedroom, the air conditioner was operated with the highest intensity mode from 9:30 P.M. to 6:00 A.M. During the operation time, the temperature decreased to a range of 18 to $20^{\circ} \mathrm{C}$, and the $\mathrm{RH}$ increased to a range of 20 to $30 \%$. The temperature continued decreasing until the air conditioning shut off the following morning, indicating the resident wanted a lower temperature. The bedroom in residence A had the lowest temperature among the houses that were measured.

b) Residence B (Figure 17): The air conditioner in the bedroom was operated at a set point temperature of $22^{\circ} \mathrm{C}$. Although the air conditioner was turned off after a short operation due to the sickness of the occupant, the room temperature rapidly decreased down to $21^{\circ} \mathrm{C}$ during the operation. This temperature can be said to be too low for sleeping. In the inquiry session, the resident answered that the air conditioner was usually operated the entire night until the following morning. Thus, although a desired temperature was not realized, the resident still wanted a lower temperature. Low airtightness, poor insulation, or the small size of the air conditioner may be the reason for this finding.

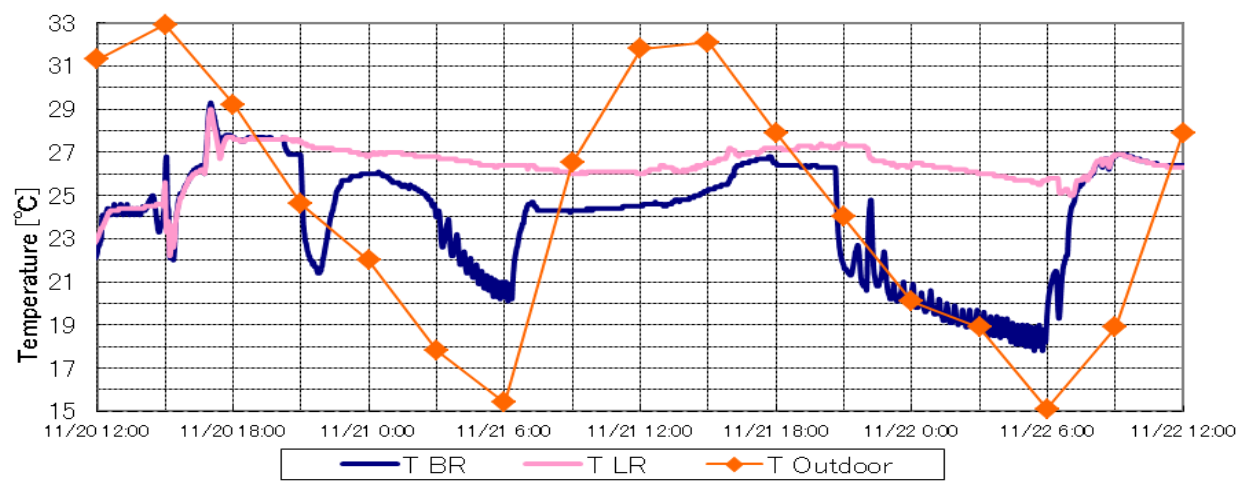

Figure 16. Living, bedroom, and outdoor temperatures (House A).

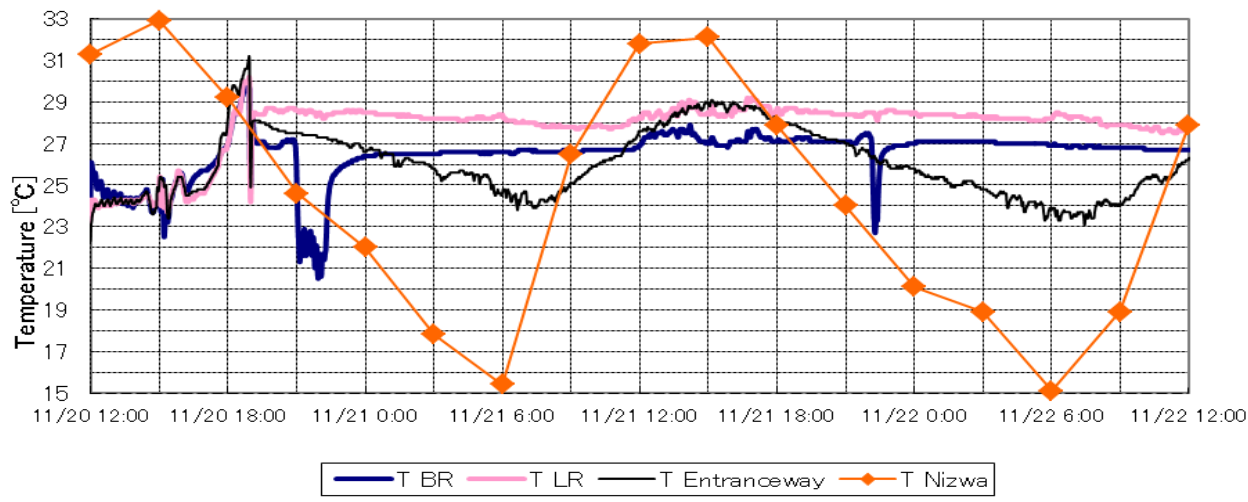

Figure 17. Living, bedroom, and outdoor temperatures (House B). 


\section{DISCUSSION}

\subsection{Comparison with Results in Kuala Lumpur and Surabaya}

Figures 18 and 19 show the results for a survey that was carried out in Kuala Lumpur, Malaysia, and Surabaya, Indonesia, in hot and humid climates (Nastiti et al., 2013). These figures correspond to Figures 14 and 15 in Oman.

The number of residents who reported having a "cold" or "cool" thermal sensation and a "very comfortable" or "comfortable" comfort sensation was quite high. The percentage was 68\% in Kuala Lumpur and $80 \%$ in Surabaya. Thus, a majority of respondents felt cold and comfortable. Among people who reported being cold or cool, about 50\% (Kuala Rumpur) and $25 \%$ (Surabaya) of respondents wanted a "cooler" environment. These results qualitatively agree very well with those in the present survey in Oman. We can only find quantitative difference for respondents who chose "as it is" (neutral) in Oman.

\subsection{Differences between previous study on thermal sensation and the present study}

There are two forms of comfort: active and passive (Horie 1961; Kuno 1987; Nagano 1997). "Active comfort" refers to an active and vibrant condition (a desire for development), while passive comfort refers to a physiologically easy condition (a desire for deficiency).

Dear et al. (1990, 1991) carried out an experiment in Singapore to calculate a neutral temperature based on the subjects' reporting of thermal sensations. The neutral temperature was $28.5^{\circ} \mathrm{C}$. On the other hand, in an experiment where the subjects chose a favorable temperature, the neutral temperature (or comfort temperature) was $25.6^{\circ} \mathrm{C}$. The reason for the three-degree difference in the two experiments seems to be accounted for by the different definitions of comfort involved. That is, the neutral temperature in the second experiment was based on active comfort, while the neutral temperature in the first experiment was based on passive comfort. In the second experiment, the subjects seem to have chosen cold and comfortable temperatures on the basis of active comfort.

Figure 20 shows the percentage of people who feel uncomfortable at each thermal sensation in Kuala Lumpur plus Surabaya, and Nizwa plus Rustak. At the cold, cool, and neutral sensations, the percentage of people who feel uncomfortable is very low in contrast with rather high percentages at the warm sensation. Although a definite conclusion is difficult since the total number of the respondents declaring warm or hot thermal sensations is very small, the profile from cool to warm sensations seems asymmetric, which indicates that the respondents in this survey tend to prefer a cold environment.
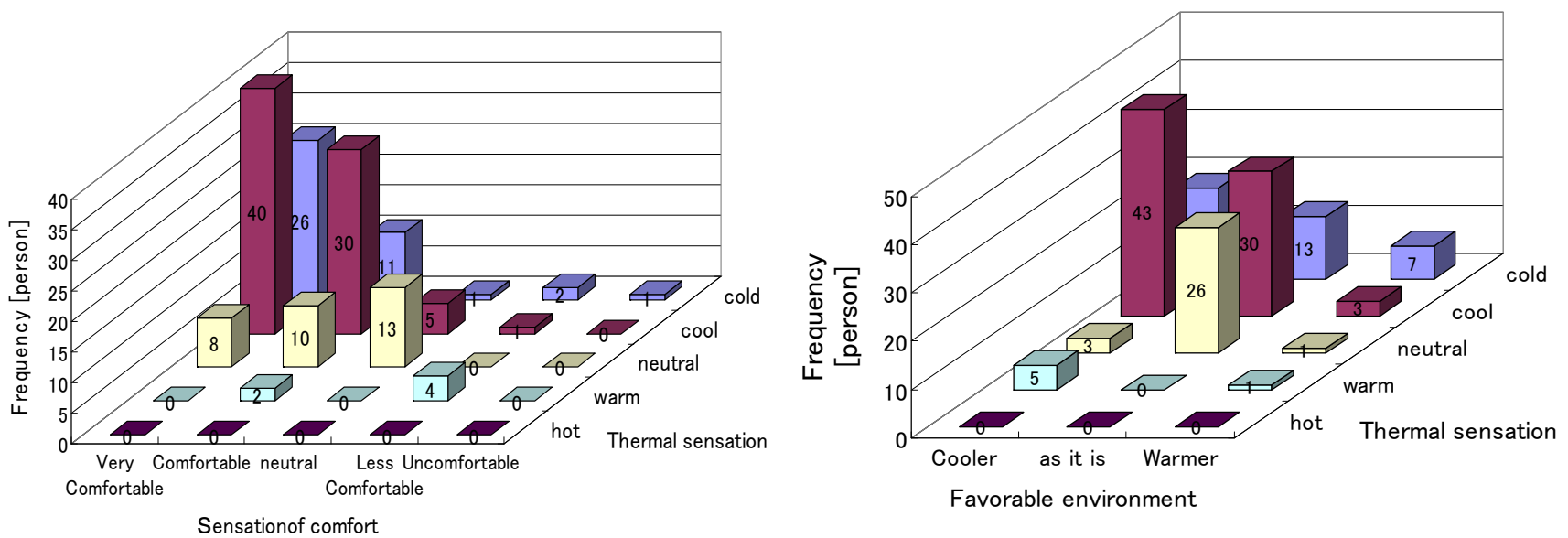

Figure 18. Breakdown of sensation of comfort and favorable environment in each thermal sensation (Kuala Lumpur) 

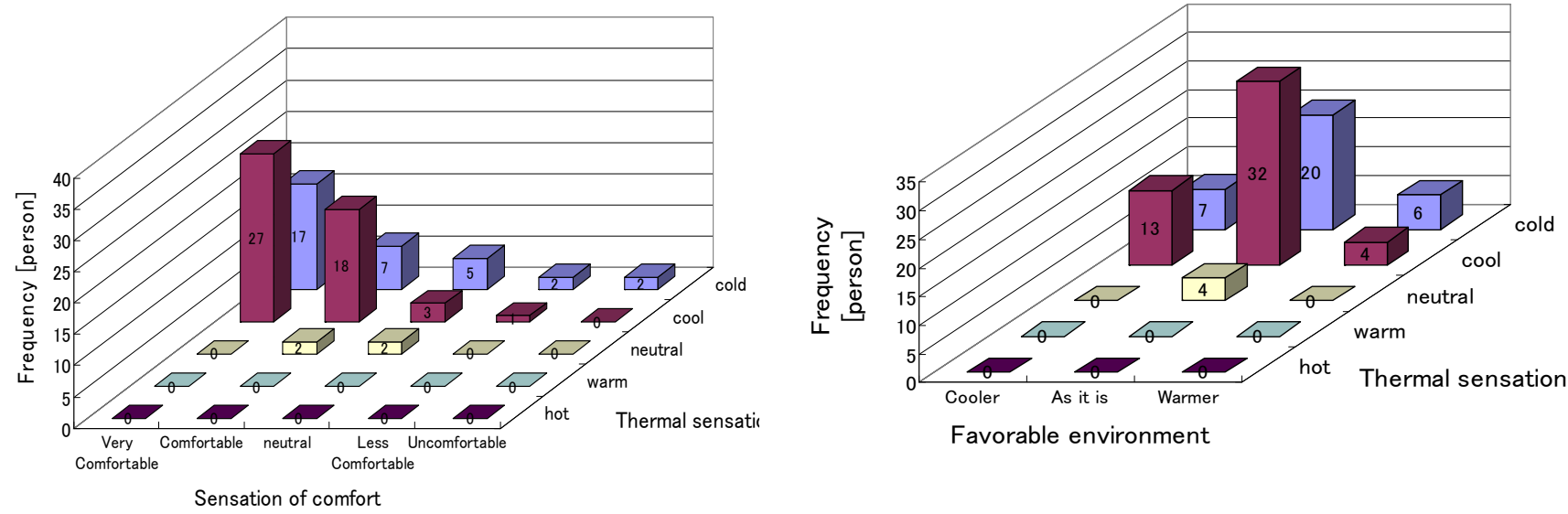

Favorable environment

. Figure 19. Breakdown of sensation of comfort and favorable environment in each thermal sensation (Surabaya)

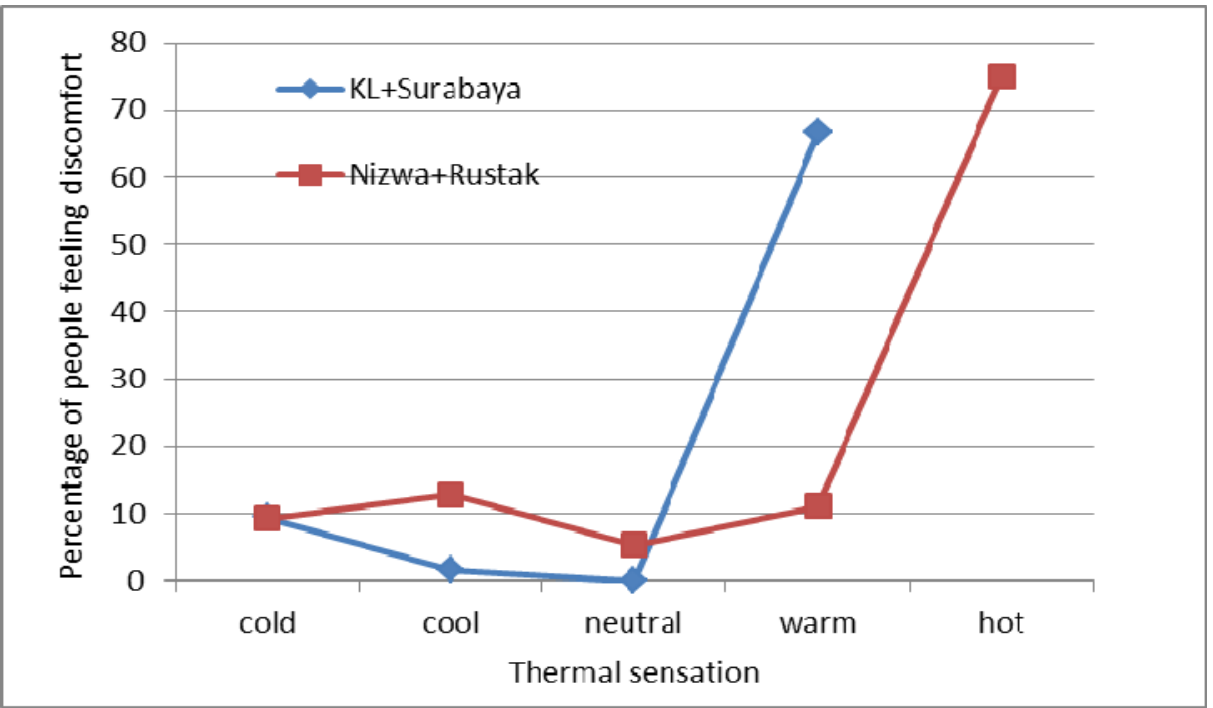

Figure 20. Percentage of people feeling uncomfortable at each thermal sensation

\section{CONCLUSION}

A questionnaire survey was conducted in Nizwa and Rustak, Oman, both of which have hot, dry climates. The purpose of this study was to identify the indoor thermal conditions created by using air conditioners in residential buildings in which residents have the opportunity to choose the temperature setting in their bedroom.

In both cities, the mean operating time reported by respondents was longer than 9 hours. The respondents reported selecting a low temperature setting while sleeping, despite the fact that many of them reported that they were cold while sleeping. Many respondents reported various health problems.

The results of a subjective assessment of indoor thermal environments and correlations between thermal and comfort sensations indicate that many people consider cold environments to be comfortable and tend to prefer cooler environments. These results are very similar to those found in hot and humid climates such as those of Indonesia and Malaysia. 


\section{ACKNOWLEDGMENTS}

This research was partially supported by the Ministry of Education, Science, Sports, and Culture, Grant-in-Aid for Scientific Research, 23656349, 2011, and TOSTEM research foundation.2008.

\section{REFERENCES}

ASHRAE. 2005. ASHRAE Handbook-Fundamentals. Atlanta: American Society of Heating Refrigeration and Air Conditioning Engineers, Inc.

J. Busch. 1992. A tale of two populations: thermal comfort in air-conditioned and naturally ventilated offices in Thailand. Energy and Buildings, 18: 235-49.

Data from World Meteorological Organization: http://www2m. biglobe.ne.jp/\%257eZenTech/ world/information /kion /indonesia_surabaya.html,http://www2m.biglobe.ne.jp/\%257eZenTech/world/infomation/kion/malaysia_kualalump ur.html.

R.J. de Dear and K. G. Low. Indoor climate and thermal comfort in high-rise public housing in an equatorial climate, A field-study in Singapore. Journal Atmospheric Environment 1990; 2(24B): 313-320.

R.J. de Dear, K.G. Leow, A. Ameen. 1991. Thermal comfort in the humid tropics- Part 1: climate chamber experiments on temperature preference in Singapore. Part 2: climate chamber experiments on thermal acceptability in Singapore. ASHRAE Transactions, 97(1): 874-86.

P.O. Fanger. 1970. Thermal Comfort Analysis and Applications in Environmental Engineering. McGraw-Hill Book Company.

G. Horie. Principles of architectural planning 3. In: Y. Watanabe. editors.: Maruzen; 1961, p. 259-283

T. Kubota and S. 2006. Ahmad. Wind Environment Evaluation of Neighborhood Areas in Major Towns of Malaysia. Journal of Asian Architecture and Building Engineering; 5(1): 199-206.

S. Kuno. et al. A two dimensional model expressing thermal sensation in transitional conditions. ASHRAE Trans. 1987; 93(2): 396-406

Ministry of Internal Affairs and Communications. 2002. Statistic Bureau.

K. Nagano, et al. Psychological and physiological influence of combined environment on non-specific evaluation: considerations based on the concept of positive and negative comfort. Architectural Institute of Japan, Kinki Branch, study report collection 1997; 69-72.

S. Nastiti N.E., N. Hanita A.M, S. Hokoi, D. Oka, N. Takagi and T. Uno 2013 Field Survey of Air Conditioner Temperature Settings in Hot, Humid Climates: Questionnaire results on use of air conditioners in houses during sleep Journal of Asian Architecture and Building Engineering, 12(1): 141-148.

J. F. Nicol. 1973. An analysis of some observations of thermal comfort in Roorkee, India and Baghdad, Iraq. Annals of Human Biology: 1(4): 411-26.

J.F. Nicol. 2004. Adaptive thermal comfort standards in the hot-humid tropics. Energy and Buildings, 36: 628-37.

M.R. Sharma and S. Ali. 1986. Tropical Summer Index-a study of thermal comfort in Indian subjects. Building and Environment, 21(1): 11-24.

T. Uno, S. Hokoi and S.N.N Ekasiwi. 2003. Survey on Thermal Environment in Residences in Surabaya, Indonesia - Use of Air-conditioner. Journal of Asian Architecture and Building Engineering, 2(2): 15-21.

\section{APPENDIX: \\ QUESTIONNAIRE FOR RESIDENTS}

Details are omitted in some questions.

About your home.

Q. 1 Your family: Please fill in your and your family members' ages and sexes in the following table.

Q. 2 Type of house

Q. 3 Number of stories

Q. 4 Structure of house

Q. 5 Electrical appliances: What kinds of electrical appliances do you have other than an air conditioner? Please fill in the number of units.

TV (), PC (), refrigerator (), washing machine (), rice cooker (), microwave oven (),

fixed-line phone () , vacuum cleaner (), electric fan ()

Q. 6 Plan of house

Q. 7 Address and map 
Q. 8 Users of the bedroom

Q. 9 Opening and closing of windows for ventilation: Please fill in the times when you open the doors and windows for ventilation. Please use the numbers from Q. 6 to identify doors and windows.

【living room 】

\begin{tabular}{|c|c|c|c|c|c|}
\hline \multirow[t]{2}{*}{ door1 } & & & & & \\
\hline & 0 & 6 & 12 & 18 & 24 \\
\hline
\end{tabular}

$\uparrow(\mathrm{ex})$

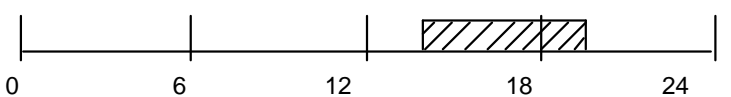

Q. 10 Electricity charge: How much is your electricity bill every month?

\begin{tabular}{|c|c|}
\hline User & $\begin{array}{r}\text { Yourself } \cdot \text { Father } \cdot \text { Mother } \cdot \text { Older sister/brother } \\
\text { Younger sister/brother } \cdot \text { Servant } \cdot \text { Relative }\end{array}$ \\
\hline Set-point temperature & ()$^{\circ} \mathrm{C}$ \\
\hline Thermal sensation & Cold $\cdot$ cool (slightly cold $) \cdot$ neutral $\cdot$ warm $($ slightly hot $) \cdot$ hot \\
\hline Comfort sensation & $\begin{array}{r}\text { Very comfortable } \cdot \text { slightly comfortable } \cdot \text { neutral } \cdot \\
\text { Slightly uncomfortable } \cdot \text { very uncomfortable }\end{array}$ \\
\hline More favorable environment & Cooler $\cdot$ as it is $\cdot$ warmer \\
\hline
\end{tabular}

Q. 11 Clothing during sleep: What kind of clothes do you and your family members wear while sleeping?

Q. 12 Annual income: If you don't mind, please choose the total annual income of your family.

Use of air conditioners.

Q. 13 Manufacturer and price

Q. 14 Usage time of air conditioner(s): When do you use the air conditioner?

Q. 15 Set-point temperature of air conditioner: Please fill in what temperature the air conditioner is set to, along with the comfort level when using it at this set-point temperature.

Q. 16 Health: Has there been any change in your health or physical condition since beginning to use the air conditioner? If so, please fill it in.

\section{ADDITIONAL QUESTIONNAIRE}

Q. 1 Do you feel that you need an air conditioner in your daily life?

Q. 2 View concerning air conditioners: What is your opinion of air conditioners?

Q. 3 Are you conscious of the economic effects of using an air conditioner?

Q. 4 Thermal environment in bedroom with air conditioner: Please choose the most appropriate description of the thermal environment in the bedroom during normal use of an air conditioner.

\section{【Bedroom 1】}

\begin{tabular}{|c|c|}
\hline User & $\begin{array}{l}\text { Yourself } \cdot \text { Father } \cdot \text { Mother } \cdot \text { Older sister/brother } \\
\text { Younger sister/brother } \cdot \text { Servant } \cdot \text { Relative }\end{array}$ \\
\hline Set-point temperature & ()$^{\circ} \mathrm{C}$ \\
\hline Thermal sensation & Cold $\cdot \operatorname{cool}($ slightly cold) $\cdot$ neutral $\cdot$ warm (slightly hot) $\cdot$ hot \\
\hline Comfort sensation & $\begin{array}{c}\text { Very comfortable } \cdot \text { slightly comfortable } \cdot \text { neutral } \cdot \\
\text { slightly uncomfortable } \cdot \text { very uncomfortable }\end{array}$ \\
\hline More favorable environment & Cooler $\cdot$ as it is $\cdot$ warmer \\
\hline
\end{tabular}

Q. 5 Countermeasures when cold (or slightly cold) in the bedroom: What are the countermeasures that you take to address coldness when using the air conditioner in the bedroom? Please circle all that apply. 
【Bedroom 1】

\begin{tabular}{|c|c|}
\hline User & $\begin{array}{c}\text { Yourself } \cdot \text { Father } \cdot \text { Mother } \cdot \text { Older sister/brother } \\
\text { Younger sister/brother } \cdot \text { Servant } \cdot \text { Relative }\end{array}$ \\
\hline 1 & Raise the set-point temperature of air conditioner \\
\hline 2 & Wear a jacket \\
\hline 3 & Wrap myself in a blanket \\
\hline 4 & Open the windows to introduce air \\
\hline 5 & Shut down the air conditioner \\
\hline 6 & Do nothing because I like a cold environment \\
\hline 7 & Endure the cold environment \\
\hline 8 & Have never felt cold \\
\hline 9 & Other ( ) \\
\hline
\end{tabular}

Q.6 Electricity use: How do you feel about electricity use? 